leee Transactions On Geoscience And Remote Sensing

October 2017, Volume 55 Issue 10 Pages 5843-5853

Achimer

http://dx.doi.org/10.1109/TGRS.2017.2715986

http://archimer.ifremer.fr/doc/00409/52013/

(c) 2017 IEEE. Personal use is permitted, but republication/redistribution

requires IEEE permission

\title{
Onto a Skewness Approach to the Generalized Curvature Ocean Surface Scattering Model
}

\author{
Saïd Faozi ${ }^{1, *}$, Johnsen Harald ${ }^{2}$, Nouguier Frédéric ${ }^{3}$, Chapron Bertrand ${ }^{3}$, Engen Geir ${ }^{2}$
}

${ }^{1}$ NOAA, Ctr Satellite Applicat \& Res, College Pk, MD 20740 USA.

${ }^{2}$ Norut, Earth Observat Dept, N-9294 Tromso, Norway.

3 IFREMER, Lab Oceanog Spatiale, F-29280 Plouzane, France.

* Corresponding author : Faozi Saïd, email address : faozi.said@noaa.gov

\begin{abstract}
:
The generalized curvature ocean surface scattering model [general curvature model (GCM)] is extended and revisited. Two key steps are addressed in this paper, namely, a necessary sea surface spectrum undressing procedure and the inclusion of a skewness phase-related component. Normalized radar cross-section (NRCS) simulations are generated at C-band for various wind conditions, polarizations, and incidence angles. Results are compared with CMOD5.n. Although the sea surface spectrum undressing procedure is a necessary step, the overall NRCS dynamic is notably affected only in low wind conditions $(<=5 \mathrm{~m} / \mathrm{s}$ ). The inclusion of the skewness phase-related component makes the most impact to the NRCS dynamic where the upwind/downwind asymmetry is clearly detectable. A good agreement between the upwind/downwind asymmetry of the extended GCM and CMOD5.n is achieved for moderate winds (approximate to $5-10 \mathrm{~m} / \mathrm{s}$ ) and moderate incidence angles (approximate to 32 degrees -40 degrees). For low incidence angles ( $<26$ degrees), the GCM tends to overestimate the upwind/downwind asymmetry compared with CMOD5.n.
\end{abstract}

Keywords: Geophysical measurements, radar cross section, remote sensing, sea surface, surface waves 


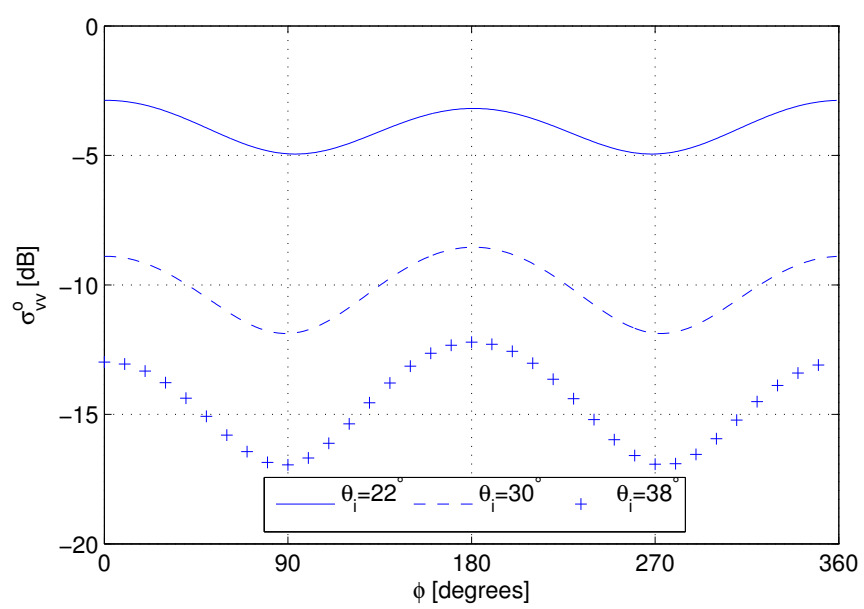

\section{INTRODUCTION}

$\mathbf{S}$ EA surface winds from radar backscatter signals are commonly inferred using a geophysical model function (GMF). Most used GMFs are semi-empirical and adapted to a specific radar instrument: NSCAT-2, QSCAT-1, QSCAT1/F13 [1], and the latest Ku-2011 [2] are some of the GMFs specifically designed to be used with backscatter data from the Ku-band scatterometer Seawind on QuikSCAT; the CMOD5.n GMF is used with at least two different C-band scatterometers, namely ASCAT [3] and ERS-2 [4].

Generating a semi-empirical GMF usually involves in-field backscatter measurements spatially and temporally collocated with either in situ wind field measurements or weather prediction models. These measurement campaigns are conducted using either satellite, aircraft, or tower-based radars [5]-[13]. There are known limiting factors, however, such as the lack of radar backscatter measurements collocated with reliable ground truth data for winds above gale force strength $(>17$ $\mathrm{m} / \mathrm{s}$ ) [14]-[16]. This in turn biases wind retrieval results and requires further GMF tuning (e.g. [17]).

A general relationship can be expressed between the radar backscatter measurements and geophysical and radar parameters

$$
\sigma^{o}=B_{0}\left[1+B_{1} \cos (\phi)+B_{2} \cos (2 \phi)\right]^{z},
$$

where the coefficients $B_{0}, B_{1}$, and $B_{2}$ are related to the wind speed, incidence angle, polarization state, radar frequency, $\phi$ is the wind direction relative to range, and the exponent $z$ is a tuning parameter [18]. Using the CMOD5.n GMF [19], Fig. 1
Fig. 1. Plot of the normalized radar cross section based on CMOD5.n, in terms of the wind direction at $V V$ polarization given a $10 \mathrm{~m} / \mathrm{s}$ wind speed and three incidence angles. $\sigma^{o}$ is maximum at upwind except at very low incidence angle. The backscattered energy also decreases as the incidence angle decreases. Several wind solutions are possible for a given $\sigma^{o}$ measurement. The wind direction, $\phi$, is relative to range where zero degree corresponds to downwind.

shows $\sigma^{o}$ in terms of the wind direction $\phi$ at $\mathrm{C}$-band given a $10 \mathrm{~m} / \mathrm{s}$ wind speed, a $V V$ polarization and three different incidence angles (22, 30, and 38 degrees). This figure shows that the backscattered energy is slightly stronger at upwind versus downwind except at low incidence angle (e.g. less than 25 degrees); $\sigma^{o}$ decreases with decreasing incidence angle, given a fixed wind speed; and as expected the backscattered energy is minimum in crosswind conditions.

GMFs can also be derived theoretically. Although this requires precise and difficult descriptions of both the electromagnetic backscattering signal from the air-sea boundary layer and of the sea surface [20]-[23]. Engen et al. developed a so-called generalized curvature ocean surface scattering model [general curvature model (GCM)], which shares some similarities with [24] where a model for the NRCS is required. The GCM preserves the well known small perturbation method (SPM) [25], the Kirchhoff approximation (KA) results [26], and obeys the fundamental laws of reciprocity and tilt invariance (preserved up to first order). [27] provides a complete and detailed theoretical description of the GCM, where a GMF is derived at C-band and tested against Envisat ASAR data (see also [28]). Since the GCM model can be used to derive the NRCS at microwave frequencies other than C-band, [29] and [30] make use of it to derive an X-band GMF, and compare its performance against TerraSAR-X stripmap data. Although 
results are promising, definite improvements can be made; the current GCM makes use of a Lagrangian surface model which includes "Stokes-like" waves (i.e. sharp crest and wide trough). However, such an implementation fails to include any vertical asymmetry to the surface wave profiles (with respect to a vertical axis going through the wave's crest), resulting in identical upwind and downwind NRCS. Several approaches in describing key characteristics of the sea surface have been proposed in the litterature in order to improve the performance of various scattering models: [31] uses a stochastic, multiscale model of the microwave backscatter from the sea surface, which includes the modulation of small and intermediate surface waves by longer waves. This model is able to show that the upwind and downwind backscatter measurements are different from each other. [32] is also able to obtain an upwind/downwind backscatter difference by including the effect of wave breaking (i.e. white cap coverage) to the description of the sea surface. Similarly, Mouche et al. (see [33]) proposes a so-called resonant curvature approximation model (RCA), which makes use of Gaussian statistical assumptions to describe the NRCS. The RCA is also able to reproduce an upwind/downwind NRCS difference by introducing a third order cumulant function, where the effect of breaking waves is assumed to be the main contributor. Mironov et al. proposes a methodology which extracts short-scale statistical characteristics of the short wind waves using stereo images of the sea surface [34]. An empirical parametrization for the skewness function is also derived in this model with similar characteristics to the one proposed by [33], which includes a directional dependency and the use of Cox \& Munk skewness coefficient [35]. Whereas [33] associates the skewness function to the effect of breaking waves, [34] argues that small-scale processes are the major contributor to the skewness function.

This paper is taking a different approach where a skewness component is introduced into the GCM model in order to improve the description of the sea surface, while leaving the fundamental expression of the NRCS (derived from the GCM) alone. Section II briefly recalls the derivation of the GCM backscatter model and introduces a skewness related phase component. Section III compares the performance of the GCM with and without the skewness phase related component at $\mathrm{C}$ band. A conclusion and discussion is provided in section IV.

\section{NRCS MODEL BASED ON THE GCM}

In this section, we briefly recall the derivation of the NRCS from [27] based on the far field relative scattered magnetic field from an illuminated area $A$ on the ocean surface, including a Lagrangian description of fluid motion [36]-[38]. The latter approach has the advantage of including non-linear wave effects (e.g. Stokes-like waves with wider trough and sharper crests as shown in Fig. 2), while solving linear equations. Following such a formalism, the normalized radar cross section is

$$
\sigma^{o}=\lim _{r_{0} \rightarrow \infty} \frac{4 \pi r_{0}^{2}}{|A|}\left\langle\left|\frac{\hat{\mathbf{H}}_{s} \cdot \mathbf{H}\left(\mathbf{r}_{\mathbf{0}}\right)}{\left|\mathbf{H}_{i}\right|}\right|^{2}\right\rangle
$$

with

$\frac{\hat{\mathbf{H}}_{s} \cdot \mathbf{H}\left(\mathbf{r}_{\mathbf{0}}\right)}{\left|\mathbf{H}_{i}\right|}=\frac{i k_{r}}{4 \pi r_{0}} \int_{A} d \mathbf{x} e^{-i\left(\mathbf{Q}_{h} \cdot \mathbf{x}+\mathbf{Q}_{r} \cdot \boldsymbol{\chi}(\mathbf{x})\right)} F(\mathbf{x}+\boldsymbol{\xi}(\mathbf{x})) J(\mathbf{x})$.

In the above equations, $\langle\cdot\rangle$ is the ensemble average operator, $\hat{\mathbf{H}}_{s}$ represents the polarization state of the scattered field, $\mathbf{H}\left(\mathbf{r}_{\mathbf{0}}\right)$ is the total field at the position $\mathbf{r}_{\mathbf{0}}$ at the center of the illuminated area $A, \mathbf{H}_{i}$ represents the incident magnetic field, $k_{r}$ is the magnitude of the radar wave vector $\mathbf{k}_{r}$ with components $\left(\mathbf{k}_{h}, k_{z}\right), \mathbf{Q}_{h}=\mathbf{k}_{h}^{s}-\mathbf{k}_{h}^{i}$, and $Q_{z}=k_{z}^{s}-k_{z}^{i}$ (superscripts $i$ and $s$ refer to incident and scattered, respectively) both components of the Ewald vector $\mathbf{Q}_{r}, \eta(\mathbf{x})$ is the sea surface elevation, and $F(\mathbf{x})$ represents a source function. The Jacobian $J(\mathbf{x})$ is defined up to first order

$$
J(\mathbf{x})=\operatorname{det}\left[\begin{array}{cc}
1+\frac{\partial \xi_{x}}{\partial x} & \frac{\partial \xi_{y}}{\partial x_{x}} \\
\frac{\partial \xi_{x}}{\partial y} & 1+\frac{\partial \xi_{y}}{\partial y}
\end{array}\right] \approx 1+\nabla \cdot \boldsymbol{\xi},
$$

where $\boldsymbol{\xi}(\mathbf{x})$ represents the horizontal displacement of a fluid particle on the sea surface at a reference point $\mathbf{x}$, with the orbital motion of the particle being described as $\chi(\mathbf{x})=(\boldsymbol{\xi}(\mathbf{x}), \eta(\mathbf{x}))$.

Assuming statistical stationarity, (2) becomes

$\sigma^{o}=\frac{k_{r}^{2}}{4 \pi} \int d \mathbf{x} e^{-i \mathbf{Q}_{h} \cdot \mathbf{x}}\left\langle e^{-i \mathbf{Q}_{r} \cdot(\boldsymbol{\chi}(\mathbf{x})-\boldsymbol{\chi}(\mathbf{0}))} F(\mathbf{x}) F^{*}(\mathbf{0}) J(\mathbf{x}) J^{*}(\mathbf{0})\right\rangle$.

Part of the Fourier kernel in the above equation can be rewritten where

$$
F(\mathbf{x}) F^{*}(\mathbf{0}) J(\mathbf{x}) J^{*}(\mathbf{0})=f(\mathbf{x}) f^{*}(\mathbf{0}),
$$

with

$$
f(\mathbf{x})=\underbrace{F^{(0)}}_{f^{(0)}}+\underbrace{\left(F^{(0)} \nabla \cdot \boldsymbol{\xi}+F^{(1)}(\mathbf{x})\right)}_{f^{(1)}}
$$

given $F^{(0)}$ and $F^{(1)}$ are the zeroth and first order source functions, respectively. Setting $\mathbf{Q}_{r} \cdot \chi=\zeta$, the Fourier kernel in (5) can now be expressed as

$$
\begin{aligned}
\left\langle e^{-i(\zeta(\mathbf{x})-\zeta(\mathbf{0}))} f(\mathbf{x}) f^{*}(\mathbf{0})\right\rangle & =e^{\varphi_{\zeta \zeta}(\mathbf{x})-\varphi_{\zeta \zeta}(\mathbf{0})} \\
{\left[\varphi_{f^{(1)} f^{(1)}}(\mathbf{x})+\right.} & \left(f^{(0)}+i\left(\varphi_{f^{(1)} \zeta}(\mathbf{x})-\varphi_{f^{(1)} \zeta}(\mathbf{0})\right)\right) \\
& \left.\left(f^{*(\mathbf{0})}-i\left(\varphi_{\zeta f^{(1)}}(\mathbf{x})-\varphi_{\zeta f^{(1)}}(\mathbf{0})\right)\right)\right]
\end{aligned}
$$

The various covariance functions $\varphi_{a b}$ in (8) can be computed using transfer functions with

$$
\varphi_{a b}(\mathbf{x})=\operatorname{Re}\left\{\frac{1}{(2 \pi)^{2}} \int d \mathbf{k} e^{i(\mathbf{k} \cdot \mathbf{x})} T_{a}(\mathbf{k}) T_{b}{ }^{*}(\mathbf{k}) \Gamma(\mathbf{k})\right\},
$$

where $T_{a}(\mathbf{k})$ and $T_{b}(\mathbf{k})$ are transfer functions, and $\Gamma(\mathbf{k})$ is the power spectral density of the sea surface elevation [39]. The required transfer functions to solve $(8)$ are $T_{\eta}(\mathbf{k})=1$,

$$
\begin{gathered}
T_{f^{(1)}}(\mathbf{k})=-k F^{(0)}+T_{F^{(1)}}(\mathbf{k}) \\
T_{\zeta}(\mathbf{k})=i \mathbf{Q}_{h} \cdot \hat{\mathbf{k}}+Q_{z}
\end{gathered}
$$

and

$T_{F^{(1)}}(\mathbf{k})=i Q_{z} F^{(0)}+\hat{\mathbf{H}}_{s} \cdot\left\{\mathcal{B}_{v v}^{(1)} \hat{\mathbf{v}}^{(1)} \hat{\mathbf{v}}^{(1)}+\mathcal{B}_{h h}^{(1)} \hat{\mathbf{h}}^{(1)} \hat{\mathbf{h}}^{(1)}\right\} \cdot \hat{\mathbf{H}}_{i}$. 


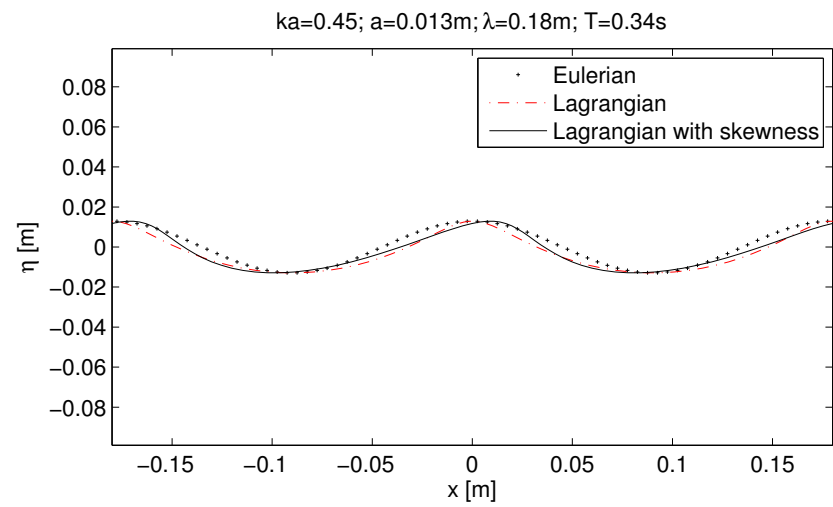

Fig. 2. Plot of a 1D deep-water small surface wave profile using a Eulerian, a Lagrangian, and a Lagrangian with skewness approaches. Wave parameters such as wave steepness, wave amplitude, wavelength, and period are shown above the plot.

In (12), $\mathcal{B}_{v v}^{(1)}$ and $\mathcal{B}_{h h}^{(1)}$ are reflection coefficients (the reader is referred to [27] for more details on these variables).

Such a model has been tested against the CMOD-IF2 GMF and compared with ASAR $\sigma^{0}$ measurements [27] [28]; it has also been tested in a wind retrieval algorithm at X-band using dual-polarized stripmap data from the TerraSAR-X instrument [29] [30]. In all cases, it has been found to perform well except when comparing up and downwind measurements; when excluding the wave breaking parameter implemented in [28], up and downwind simulated backscatter values are always equal regardless of geophysical conditions when in fact there is almost always a noticeable difference between the two. Although the current Lagrangian implementation provides an improved sea surface wave description by including Stokeslike waves (see Fig. 2), wave profile asymmetry relative to the vertical axis is missing. The latter may account for differences in up and downwind $\sigma^{0}$ measurements as discussed in the following subsection.

\section{A. Skewness related phase component}

Three major phenomena drives the skewness of the sea surface slope probability density function (pdf): the presence of parasitic capillary waves on the forward face of short gravity waves, the presence of breaking waves, and the actual tilting of the waves themselves when these approach maximum steepness $(k a \sim 0.44)$ [40]. As previously mentioned, our approach consists in incorporating both the effect of breaking waves and the tilting of the waves into the GCM. Wave profile asymmetry relative to the vertical axis can easily be introduced to the current Lagrangian implementation by replacing

$$
\tilde{\mathbf{x}}=\mathbf{x}+\boldsymbol{\xi}(\mathbf{x})
$$

with

$$
\tilde{\mathbf{x}}=\mathbf{x}+\boldsymbol{\xi}(\mathbf{x}, \alpha)
$$

where $\alpha$ represents a phase coefficient which can be determined empirically. Figure 2 shows the 1D profile of a deep-water small wave when including a phase coefficient $\alpha=\pi / 4$ where $\eta=a \cos (k x)$ and $\tilde{x}=x-a \sin (k x-\alpha)$

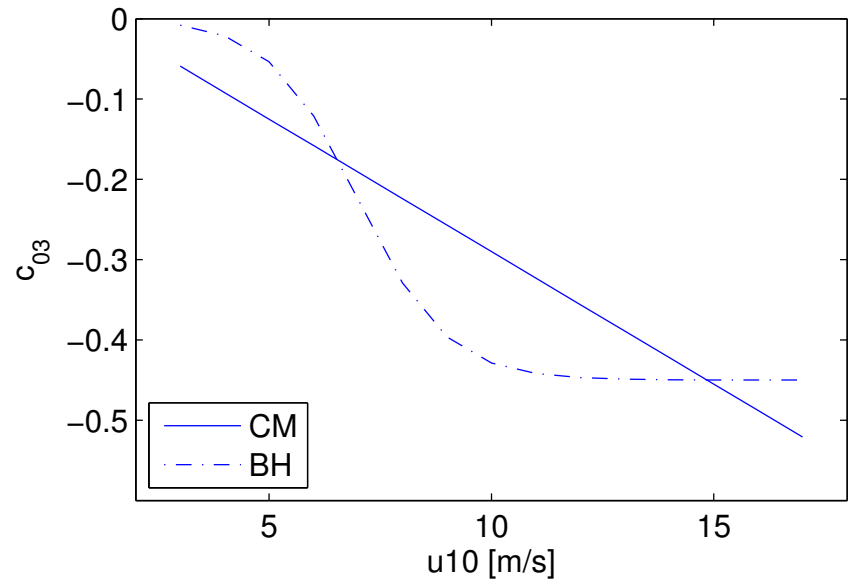

Fig. 3. Comparison of Cox \& Munk empirical up/down wind skewness coefficients vs. Bréon and Henriot's.

(see 'Lagrangian with skewness' in the legend). The inclusion of this new phase clearly tilts the wave forward, which in turn skews the surface slope pdf. Cox \& Munk [35] made quantitative measurements and analysis of the sea surface roughness including the statistics of the slope distribution for various wind speeds. Bréon \& Henriot [41] performed a similar analysis using spaceborne observations of ocean glint reflectance instead. Both methods provide a model of wave slope distributions where the up/downwind skewness coefficient is expressed as

$$
c_{03 C M}=.04-.033 \cdot \mathrm{u}_{10},
$$

from Cox \& Munk (CM) and

$$
c_{03 B H}=-.45 *\left(1+e^{7-\mathrm{u}_{10}}\right)^{-1},
$$

from Bréon \& Henriot (BH). Figure 3 shows a plot of these up/down wind skewness coefficients in terms of wind speed. Note how the up/downwind skewness coefficient from BH increases rapidly between 6 and $9 \mathrm{~m} / \mathrm{s}$ while becoming steady for higher wind speeds; whereas CM's linearly increases with wind speed.

In order to determine the proper amount of phase $\alpha$, a 3D surface is generated with random phases $\beta_{r}$, similar to [38], using

$$
\begin{gathered}
\xi(\mathbf{x})=i \int d \mathbf{k} \hat{\mathbf{k}} e^{i \mathbf{k} \cdot \mathbf{x}} \sqrt{\Gamma(\mathbf{k})} e^{i \beta_{r}} e^{i \alpha}, \\
\eta(\mathbf{x})=\int d \mathbf{k} e^{i \mathbf{k} \cdot \mathbf{x}} \sqrt{\Gamma(\mathbf{k})} e^{i \beta_{r}},
\end{gathered}
$$

with

$$
\begin{array}{rr}
\alpha=A \cos \phi, & k<62.8 \mathrm{rad} . \mathrm{s}^{-1} \\
\alpha=0, & k>62.8 \mathrm{rad} . \mathrm{s}^{-1}
\end{array}
$$

where $\hat{\mathbf{k}}=\frac{\mathbf{k}}{|k|}, \Gamma(\mathbf{k})$ is the Elfouhaily sea surface spectrum which assumes a fully developped sea free of incoming swells [42], $A$ is the phase coefficient amplitude, and $\phi$ is the angle between the wave and the wind directions. As an illustration, Fig. 4 shows two simulated 3D surfaces, on a $1.4 \times 1.4 \mathrm{~m}$ surface patch, with $\alpha=-.21875 \cos \phi$ for $u_{10}=5 \mathrm{~m} / \mathrm{s}$ and $\alpha=$ 

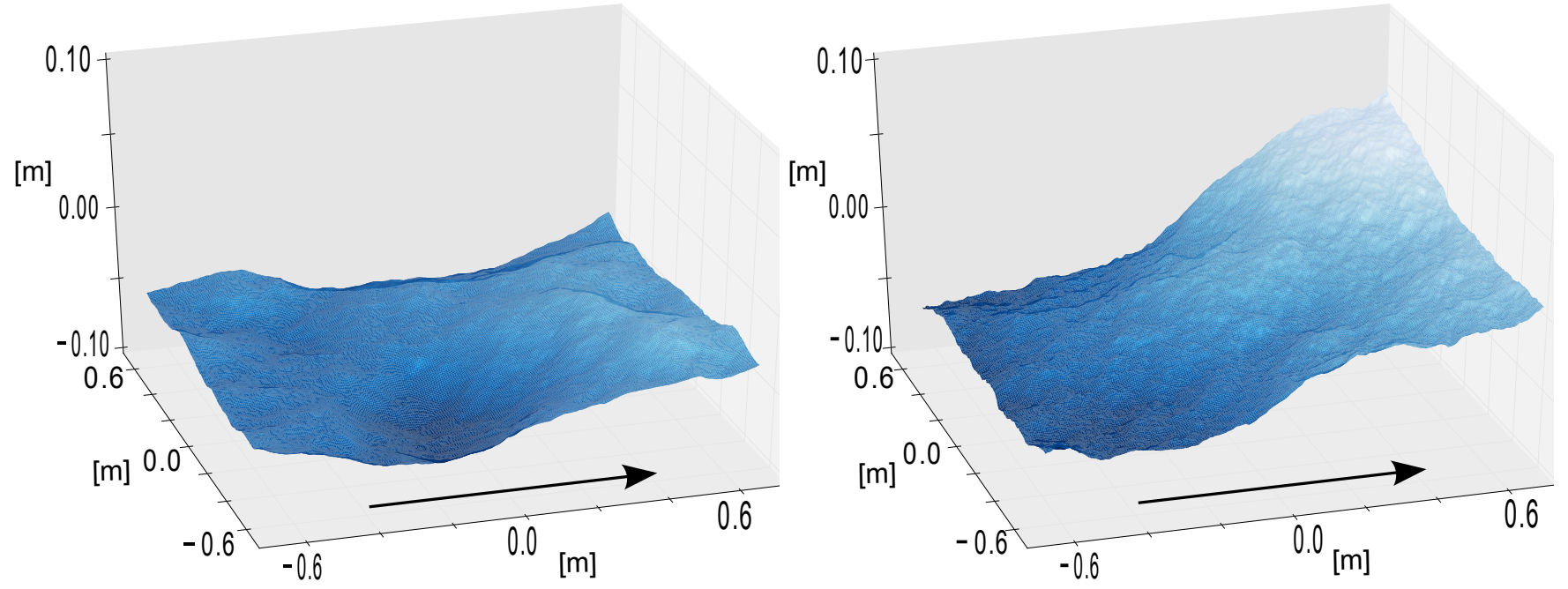

Fig. 4. Plots of two simulated 3D surfaces using the Elfouhaily sea surface spectrum, on a $1.4 \mathrm{x} 1.4 \mathrm{~m}$ surface patch, for $u_{10}=5 \mathrm{~m} / \mathrm{s}$ (left plot) and $10 \mathrm{~m} / \mathrm{s}$ (right plot). The black arrow indicates the wind direction.

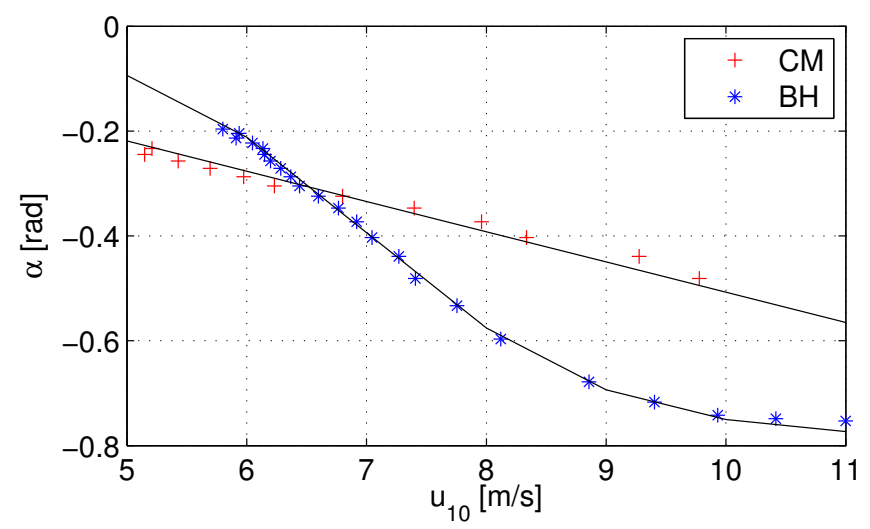

Fig. 5. Plot of the phase amplitude $\alpha$ vs. wind speed for both empirical skewness coefficients from $\mathrm{CM}$ and $\mathrm{BH}$.

$-.50750 \cos \phi$ for $u_{10}=10 \mathrm{~m} / \mathrm{s}$, respectively. Note that the $\alpha$ term comes into play for waves with wavelengths greater than $\sim 10 \mathrm{~cm}$ (i.e. $k<62.8$ rad. ${ }^{-1}$ ). Following the assumption that short gravity waves with wavelengths greater than $10-15 \mathrm{~cm}$ no longer generate parasitic capillary waves [43], we surmise that the major source of skewness beyond this range would be from the actual tilting of the wave profile as long as breaking waves are absent. The up/down wind skewness coefficient is estimated by both computing the gradient of the generated sea surface and using the basic definition of skewness

$$
c_{03}=\frac{\kappa_{3}}{\kappa_{2}^{3 / 2}},
$$

where $\kappa_{2}$ and $\kappa_{3}$ represent second- and third-order cumulants. A long series of 3D surfaces are generated for various combinations of $\alpha$ and $\mathrm{u}_{10}$ values. A best fit is performed with the empirically derived skewness coefficients from both Cox \& Munk [35] and Bréon \& Henriot [41] (see Fig. 5), which leads to the following relationship

$$
A\left(\mathrm{u}_{10}\right) \approx 1.75 c_{03}
$$

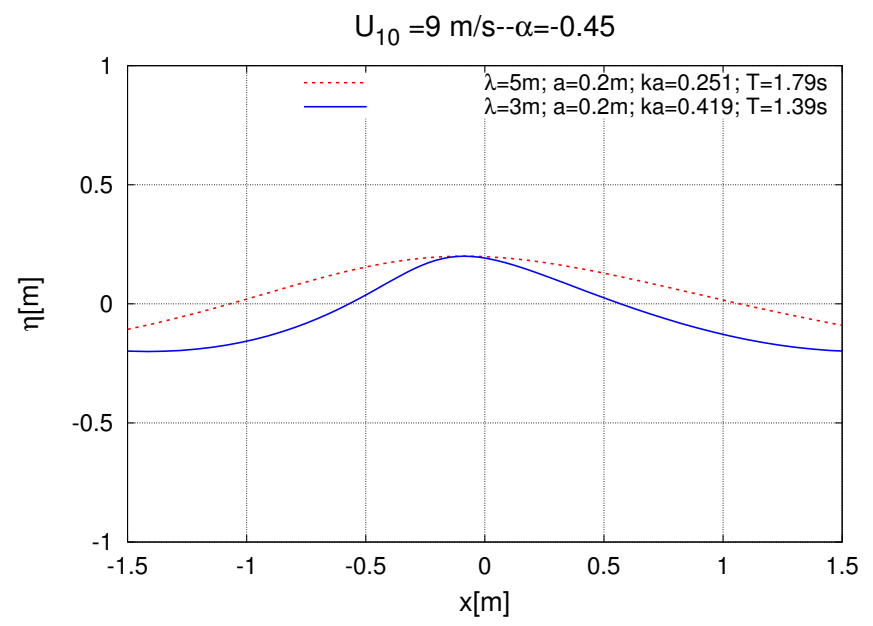

Fig. 6. Plot of two 1D deep-water small surface wave profiles using the Lagrangian with skewness approach, with $\alpha=-0.45$. The skewness parameter has less impact on the longer wave, given the same wave amplitude and wind conditions.

The above equation shows that the phase coefficient amplitude $\alpha$ increases as the wind speed increases. We note, however, that this does not necessarily lead to longer waves having their vertical wave profiles more tilted than shorter waves, as shown in Fig. 6; two waves with different wavelengths are plotted in this figure using a fixed value of $\alpha$. We can clearly see how the parameter $\alpha$ has less impact on the longer wave.

The inclusion of this phase in (14) leads to slightly different transfer functions where (10) and (11) now become

$$
T_{f^{(1)}}(\mathbf{k})=-k F^{(0)} e^{i \alpha}+T_{F^{(1)}}(\mathbf{k})
$$

and

$$
T_{\zeta}(\mathbf{k})=i \mathbf{Q}_{h} \cdot \hat{\mathbf{k}} e^{i \alpha}+Q_{z}
$$

In the following section, we analyze the impact of this new implementation into the GCM based backscatter model by 

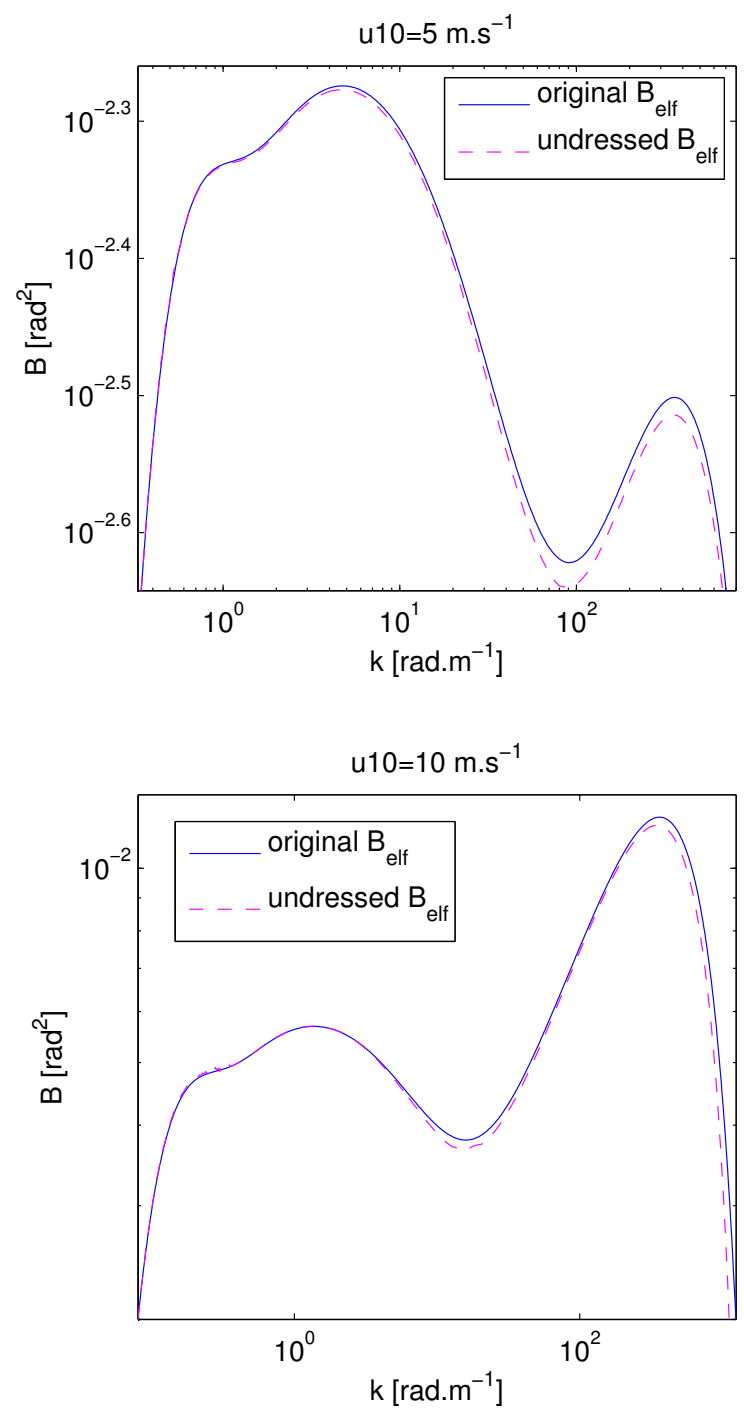

Fig. 7. Plots of the original and undressed Elfouhaily curvature spectra. The top and bottom plots correspond to $\mathrm{u}_{10}=5$ and $10 \mathrm{~m} / \mathrm{s}$, respectively.

gauging its performance against the semi-empirical CMOD5.n GMF.

\section{SimUlation ANALYSIS}

Prior to performing simulation analysis plots against CMOD5.n, it is important to remind the reader that an expression for the sea surface elevation spectrum is required for the NRCS estimation. For this study, the so-called improved unified directional spectrum developed by Elfouhaily is selected [42]. Its expression is

$$
\tilde{\Gamma}(\mathbf{k})=\frac{1}{2 \pi} k^{-4}\left[B_{l}+B_{h}\right][1+\Delta(k) \cos 2 \phi],
$$

where $B_{l}$ and $B_{h}$ refer to low and high frequencies curvature spectra, respectively, $\Delta(k)$ refers to the spreading function, and $\phi$ is the wave direction relative to the wind (for further details about these functions, see [42]).

In previous studies where the GCM based GMF is used (see [27], [29], [44], [45]), the Elfouhaily sea surface spectrum is directly implemented into (9) to estimate the NRCS. However, it is important to note that the use of a Lagrangian description of fluid motion can have adverse effects on the used sea surface spectrum. These potential issues can be avoided by using a sea surface elevation spectrum 'undressing' method as prescribed in [38] and [46]. Figure 7 compares the original Elfouhaily curvature spectrum with its undressed version after three iterations, for $\mathrm{u}_{10}=5 \mathrm{~m} / \mathrm{s}$ and $\mathrm{u}_{10}=10 \mathrm{~m} / \mathrm{s}$. In both cases, we note a slight decrease of energy for the Bragg-scale waves spectrum, which in turn should affect estimated NRCS.

\section{A. Undressed sea surface spectrum impact on NRCS}

A straightforward performance analysis of the spectra undressing impact can be done by generating the NRCS as described in [27], while using an undressed vs. dressed spectra. Figures 8 and 9 show the comparison results for C-band at both $H H$ and $V V$ polarizations, for three incidence angles $(26,32$, and 40 degrees), and for $\mathrm{u}_{10}=5$ and $10 \mathrm{~m} / \mathrm{s}$, respectively. For both polarizations, the use of an undressed spectrum slightly affects the NRCS dynamic range particularly at $\mathrm{u}_{10}=5 \mathrm{~m} / \mathrm{s}$ (see Fig. 8) regardless of incidence angle, while leaving the NRCS almost unchanged as the wind speed increases (see Fig. 9). Figure 10 shows that there is an absolute difference of $\sim 0.2$ $0.5 \mathrm{~dB}$ in the up/down wind direction, and $\sim 0.1 \mathrm{~dB}$ in the cross wind direction across the whole range of incidence angles for $\mathrm{u}_{10}=5 \mathrm{~m} / \mathrm{s}$ and both polarizations. For $\mathrm{u}_{10}=10 \mathrm{~m} / \mathrm{s}$, however, the absolute difference is small with $\sim 0.02-0.03 \mathrm{~dB}$ in the up/down wind direction, and $\sim 0.12-0.13 \mathrm{~dB}$ in the cross wind direction across the whole range of incidence angles, for both polarizations.

Even though the overall impact appears negligible, we conclude that care must be taken when a Lagrangian description of fluid motion is implemented into an NRCS model particularly at low wind speed. The subsequent simulation analysis strictly makes use of an undressed sea surface spectrum.

\section{B. Skewness implementation analysis}

The GCM backscatter model is now compared with and without the skewness related phase parameter introduced in subsection II-A, using the best fit from Cox \& Munk and Bréon \& Henriot coefficients. Figure 11 shows simulated $\sigma_{H H}^{o}$ and $\sigma_{V V}^{o}$ in terms of wind direction for $\mathrm{u}_{10}=5 \mathrm{~m} / \mathrm{s}$ and three incidence angles $\left(\theta_{i}=26,32\right.$, and $\left.40^{\circ}\right)$; Cmod5.n is added for reference for the $V V$ polarization and the NRCS derived from the Lagrangian implementation is also included. For both polarizations, the up/down wind asymmetry is now present when using the skewness related phase parameter derived from either $\mathrm{CM}$ or $\mathrm{BH}$ empirical results. This asymmetry is slightly more pronounced, however, with the former on all six plots of Fig. 11. Figure 12 provides a similar comparison as Fig. 11, but for $\mathrm{u}_{10}=10 \mathrm{~m} / \mathrm{s}$. In this case, the up/down wind asymmetry using the skewness parameters derived from either $\mathrm{CM}$ or $\mathrm{BH}$ is clearly apparent on all plots of Fig. 12, and noticeably larger than shown in Fig. 11 regardless of polarization and incidence angle.

In order to properly quantify the impact of the skewness implementation, a comparison is performed for a wider incidence angle range at the $V V$ polarization with the NRCS 

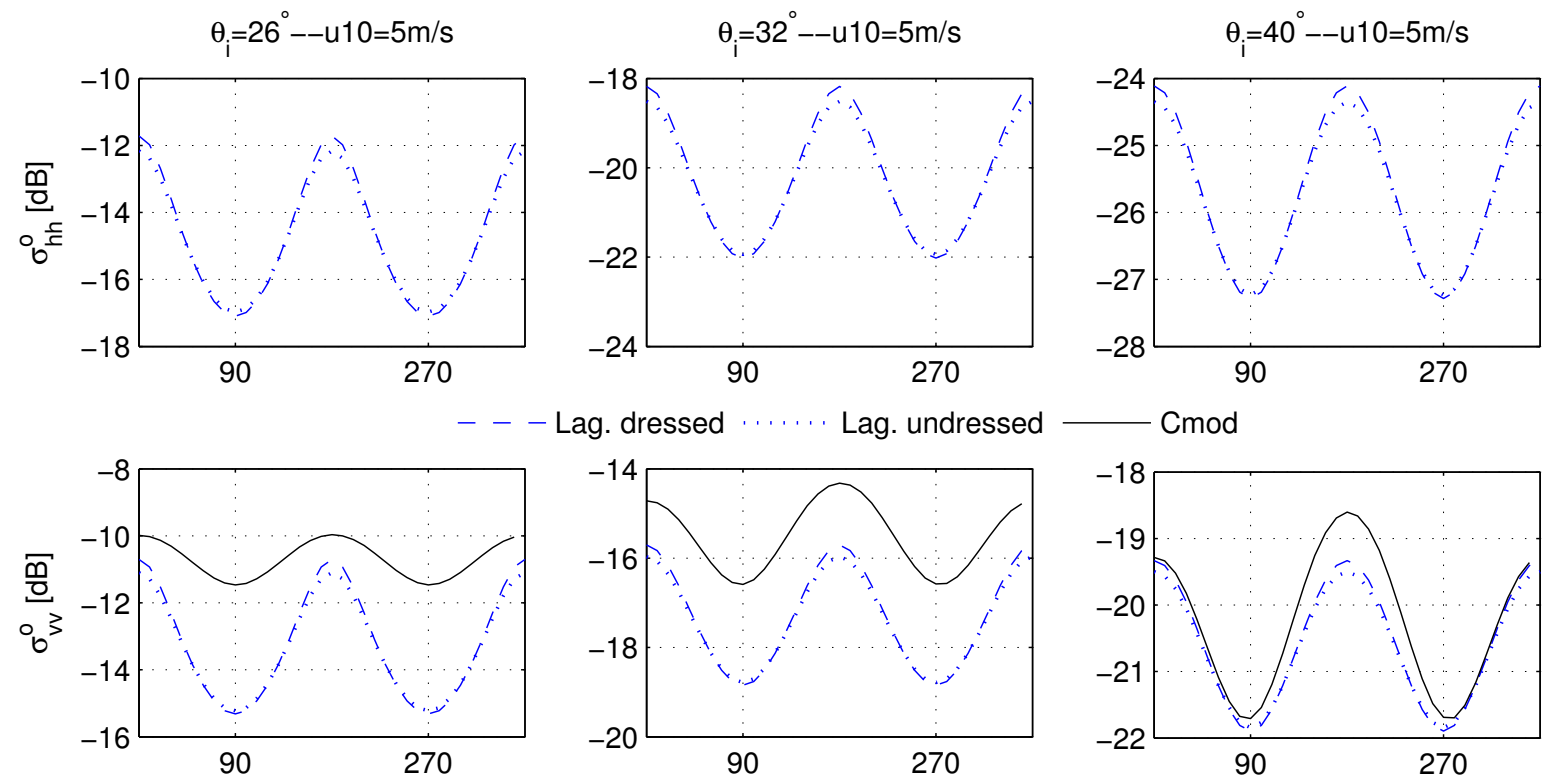

Fig. 8. Plots showing the impact of using an undressed vs. dressed spectrum into a backscatter model which makes use of a Lagrangian implementation for both $H H$ and $V V$ polarization. For the $V V$ polarization, the NRCS from Cmod5.n is included for reference. Analysis is done for $\mathrm{u}_{10}=5 \mathrm{~m} / \mathrm{s}$, and three different incidence angles (26, 32, and 40 degrees).
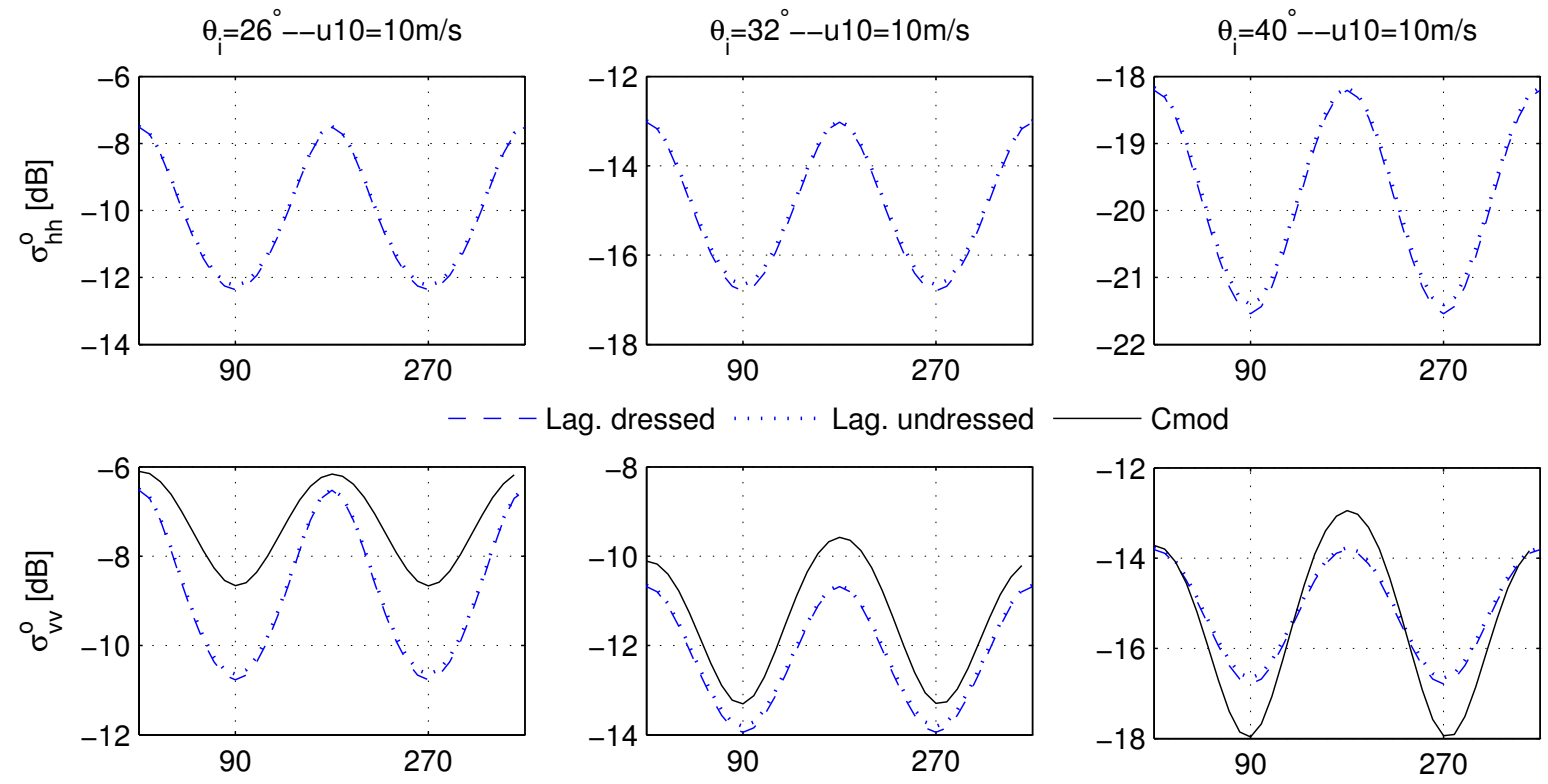

Fig. 9. Repeat of Fig. 9 but for $\mathrm{u}_{10}=10 \mathrm{~m} / \mathrm{s}$.

from Cmod5.n used as reference. Figure 13 provides two plots showing the $\sigma_{V V}^{o}$ difference, between the NRCS derived from either the $\mathrm{CM}$ or $\mathrm{BH}$ skewness related phase parameter and Cmod5.n, as a function of incidence angle given an up and downwind wind directions and a 5 and $10 \mathrm{~m} / \mathrm{s}$ wind speeds. For a $5 \mathrm{~m} / \mathrm{s}$ wind speed we first note that the $\sigma_{V V}^{o}$ difference in the upwind direction, between the NRCS derived with the CM skewness parameter and CMOD5.n, is consistenly smaller than the one derived from $\mathrm{BH}$ for all incidence angles. The opposite is true, however, in the downwind direction. Additionally, both implementations converge as the incidence angle increases. Finally, both skewness implementations yield the following results: the smallest $\sigma_{V V}^{o}$ difference in the upwind direction is obtained at low incidence angle around $25^{\circ}$ and at high incidence angle around $40^{\circ}$ in the downwind direction; while the largest difference occurs around $27^{\circ}$ in the downwind direction and $\sim 32.5^{\circ}$ in the upwind direction.

For a $10 \mathrm{~m} / \mathrm{s}$ wind speed (see bottom plot of Fig. 13), similar results are obtained in the downwind direction with the exception that the CM skewness implementation provides improved performance across all incidence angles. Results are quite different in the upwind direction where both skewness implementations have the NRCS deviate the most at low incidence angle; the CM implementation has a minimal $\sigma_{V V}^{o}$ 


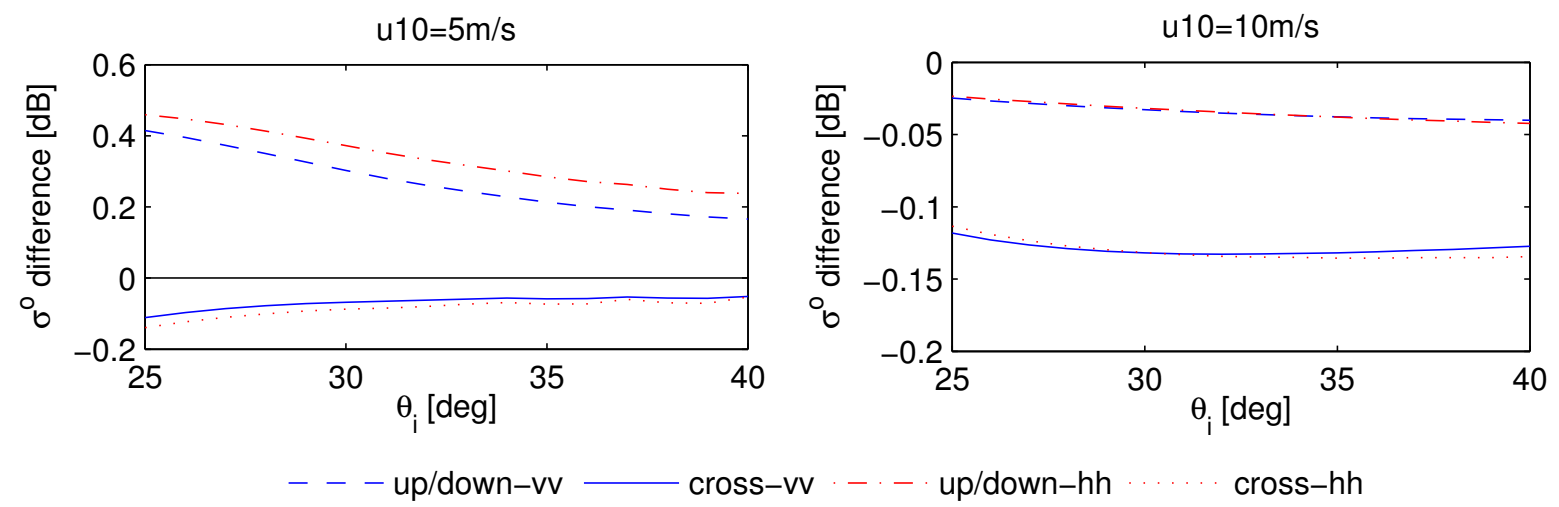

Fig. 10. $\sigma^{o}$ difference from the Lagrangian undressed and Lagrangian dressed as a function of incidence angle given an up/down and cross wind directions. This comparison is done for a 5 and $10 \mathrm{~m} / \mathrm{s} \mathrm{u}_{10}$.

difference with CMOD5.n around $32.5^{\circ}$ incidence angle, while the $\mathrm{BH}$ implementation has it around $37.5^{\circ}$ incidence angle. In either up or downwind directions, both implementation converge as the incidence angle increases.

For wind speeds greater than $10 \mathrm{~m} / \mathrm{s}$, wave breaking effects (i.e. wave crests becoming unstable and dissipating energy in the form of foam) must be taken into consideration. In [28] and [32], this effect has been implemented into the GCM such that

$$
\sigma_{\alpha \alpha}^{o}=\sigma_{g c m}^{o}(1-q)+\sigma_{w b}^{o} q,
$$

where $\sigma_{\alpha \alpha}^{o}$ refers to the polarization state, $\sigma_{g c m}^{o}$ refers to the NRCS derived from the GCM, $\sigma_{w b}^{o}$ refers to the NRCS derived from non-Bragg scattering from breaking waves, and $q$ is the fraction of the sea surface area covered by breaking waves. The reader is refered to [32] for further details on the derivation of $\sigma_{w b}^{o}$ and $q$. Figure 14 shows simulated $\sigma_{H H}^{o}$ and $\sigma_{V V}^{o}$ in terms of wind direction for $\mathrm{u}_{10}=15 \mathrm{~m} / \mathrm{s}$ using the GCM with and without the wave breaking component. This simulation is performed using the Lagrangian implementation with an undressed sea surface spectrum. In this case, the inclusion of the $\alpha$ parameter is unnecessary since the wave breaking component already includes effects from Cox \& Munk skewness coefficient [32]. Just as when the skewness related phase parameter is included, we note in Fig. 14 a noticeable difference between the up and downwind NRCS when the wave breaking component is implemented with the GCM. The breaking wave implementation also introduces a positive bias $(\sim 1-2 \mathrm{~dB})$ in the NRCS across all wind directions, for all three incidence angles and both polarizations. Figure 15 shows the bias between the NRCS, derived with and without the breaking wave effect, against the NRCS from CMOD5.n; this bias is almost non-existent $(\sim 0.1-0.3 \mathrm{~dB})$ when the breaking wave effect is included in both the up and downwind directions.

\section{CONCLUSION}

In this paper, the generalized curvature ocean surface scattering model introduced in [27] is revisited. Such a scattering model requires a statistical description of the sea surface including the use of the sea surface spectrum from Elfouhaily [42], in order to simulate the NRCS. The original version of the GCM makes use of a Lagrangian description of fluid motion so as to improve the sea surface description from simple sinusoidal like waves to "Stokes-like" surface waves. [38] dictates the use of a sea surface spectrum undressing procedure when a Lagrangian description of fluid motion is implemented. This method was applied in this paper to the GCM at C-band where its impact, albeit minimal, was most noticeable for $u_{10}=5 \mathrm{~m} / \mathrm{s}$; an absolute difference of $\sim 0.2-0.5 \mathrm{~dB}$ in the up/down wind direction and $\sim 0.1 \mathrm{~dB}$ in the cross wind direction resulted across the whole range of incidence angles for both polarizations. The impact of the undressing procedure was almost negligible for $u_{10}=10 \mathrm{~m} / \mathrm{s}$ where an absolute difference of $\sim 0.02-0.03 \mathrm{~dB}$ was found in the up/down wind direction and $\sim 0.12-0.13 \mathrm{~dB}$ in the cross wind direction across the whole range of incidence angles at both polarizations.

The major aim of this paper was to improve the description of the sea surface used in the GCM, by introducting asymmetry to the vertical profile of sea surface waves. The use of a so-called skewness related phase component was implemented into the GCM by modifying the horizontal component describing the propagation of waves along the sea surface. Empirical up/down wind skewness coefficients measured by Cox \& Munk (CM) as well as Bréon \& Henriot (BH) were respectively used to derive the skewness related phase component. Simulations were performed at C-band where the NRCS was first generated for low to moderate wind conditions ( 5 and $10 \mathrm{~m} / \mathrm{s}$ ) for both polarizations ( $H H$ and $V V$ ). Results were compared with CMOD5.n for 26, 32 , and $40^{\circ}$ incidence angles for all wind directions. For $\mathrm{u}_{10}=5 \mathrm{~m} / \mathrm{s}$, the up/down wind asymmetry was now present in the NRCS for both polarizations when using either the $\mathrm{CM}$ or $\mathrm{BH}$ empirical results, although results were more pronounced using the former. For $\mathrm{u}_{10}=10 \mathrm{~m} / \mathrm{s}$, the up/down wind asymmetry was clearly noticeable and at times exagerated when compared to CMOD5.n, particularly at lower incidence angles (e.g. $<30^{\circ}$ ); up to a $5 \mathrm{~dB}$ difference was found between the up and downwind NRCS, whereas CMOD5.n indicated an almost non-existence up/downwind difference. For the respective NRCS derived from CM and BH skewness coefficients, the up and downwind $\sigma_{V V}^{o}$ bias with CMOD5.n 

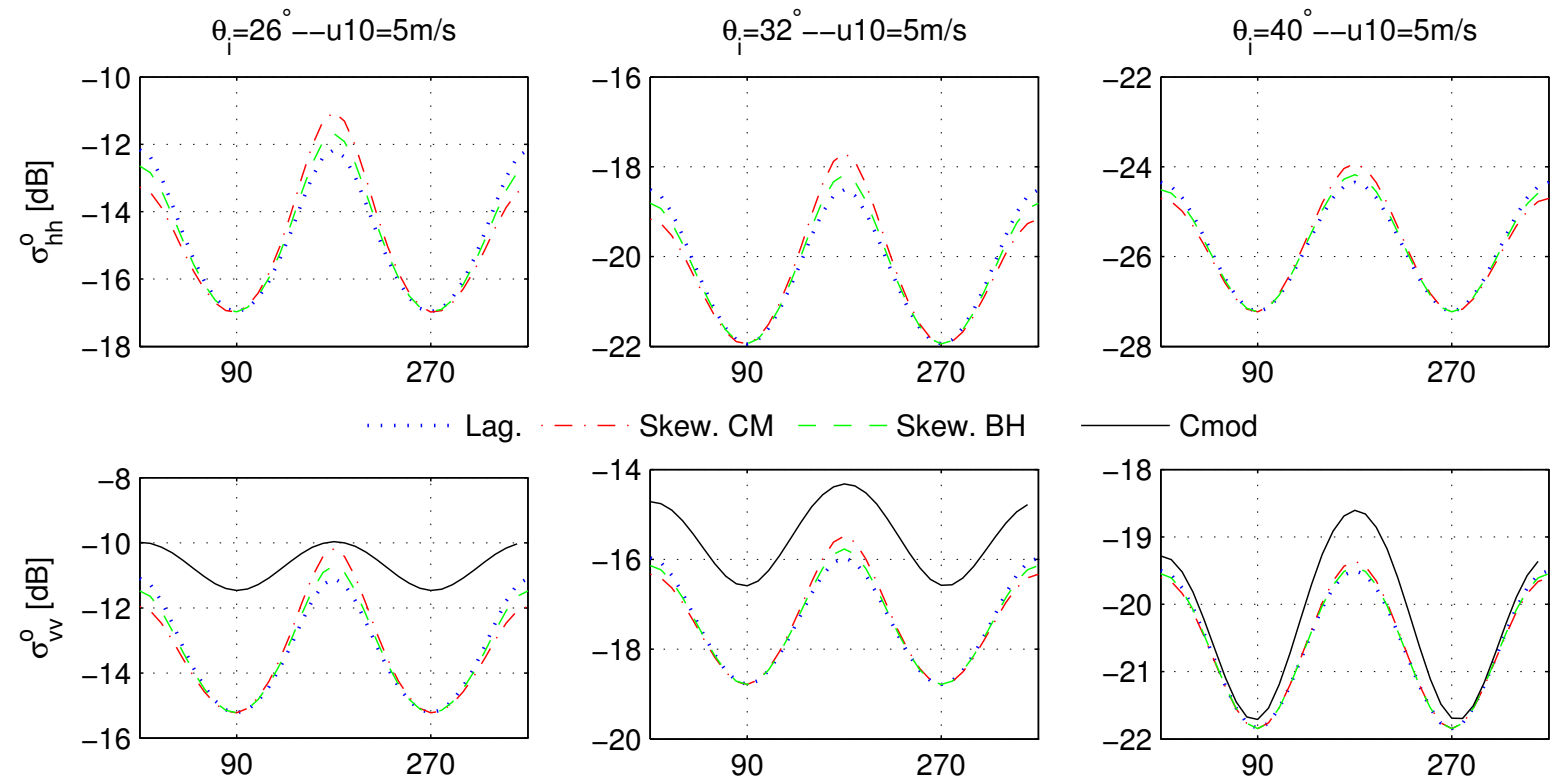

Fig. 11. Comparison of the GCM backscatter model with and without the skewness related phase parameters derived, respectively, from CM and BH empirical results. Cmod5.n is also included for reference for the $V V$ polarization. Analysis is done for a $5 \mathrm{~m} / \mathrm{s} \mathrm{u}_{10}$, and three different incidence angles $(26,32$, and 40 degrees).
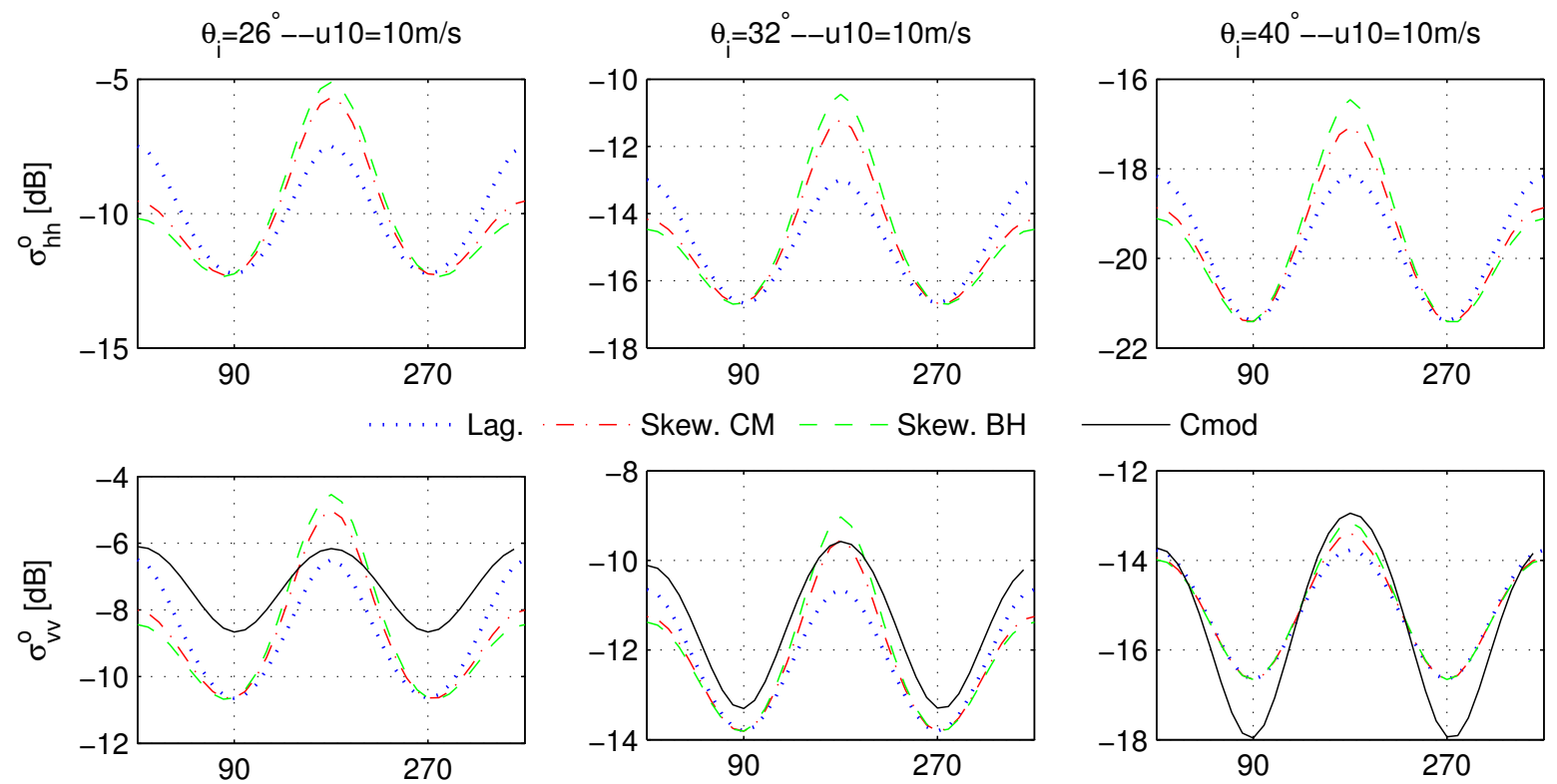

Fig. 12. Repeat of Fig. 11 but for $\mathrm{u}_{10}=10 \mathrm{~m} / \mathrm{s}$.

were also computed for incidence angles between 25 and $40^{\circ}$, respectively for $\mathrm{u}_{10}=5$ and $10 \mathrm{~m} / \mathrm{s}$. For both wind speeds, the $\sigma_{V V}^{o}$ bias with either $\mathrm{CM}$ or $\mathrm{BH}$ based skewness related phase parameter remained close to $2 \mathrm{~dB}$ in the downwind direction for incidence angles below $30^{\circ}$. This bias decreased as the incidence angle increased and became almost non-existent for $\theta_{i}$ around $40^{\circ}$. The upwind $\sigma_{V V}^{o}$ biases for $\mathrm{u}_{10}=5 \mathrm{~m} / \mathrm{s}$ remained within $1.5 \mathrm{~dB}$ throughout the incidence angles. For $\mathrm{u}_{10}=10 \mathrm{~m} / \mathrm{s}$, up to $2 \mathrm{~dB}$ biases were found for low incidence angles, with smaller biases for higher incidence angles $(\sim 0.5$ $\mathrm{dB})$.

For wind speeds above $10 \mathrm{~m} / \mathrm{s}$, wave breaking effects were taken into consideration by including contributions from nonBragg scattering to the NRCS. Since this approach already included effects from CM skewness coefficients, our skewness related phase parameter was excluded from the Lagrangian description of the sea surface. For $\mathrm{u}_{10}=15 \mathrm{~m} / \mathrm{s}$, the inclusion of breaking wave effects resulted in a positive bias of 1-2 $\mathrm{dB}$ in the NRCS across all wind directions for 26,32 , and $40^{\circ}$ incidence angles, and for both polarizations. The $\sigma_{V V}^{o}$ bias in the up/down wind direction with CMOD5.n were also compared across all incidence angles. The inclusion of the breaking wave effects resulted in $\sim 0.1-0.3 \mathrm{~dB}$ biases in the up/down wind directions, compared to $\sim 0.1-1 \mathrm{~dB}$ without it. 

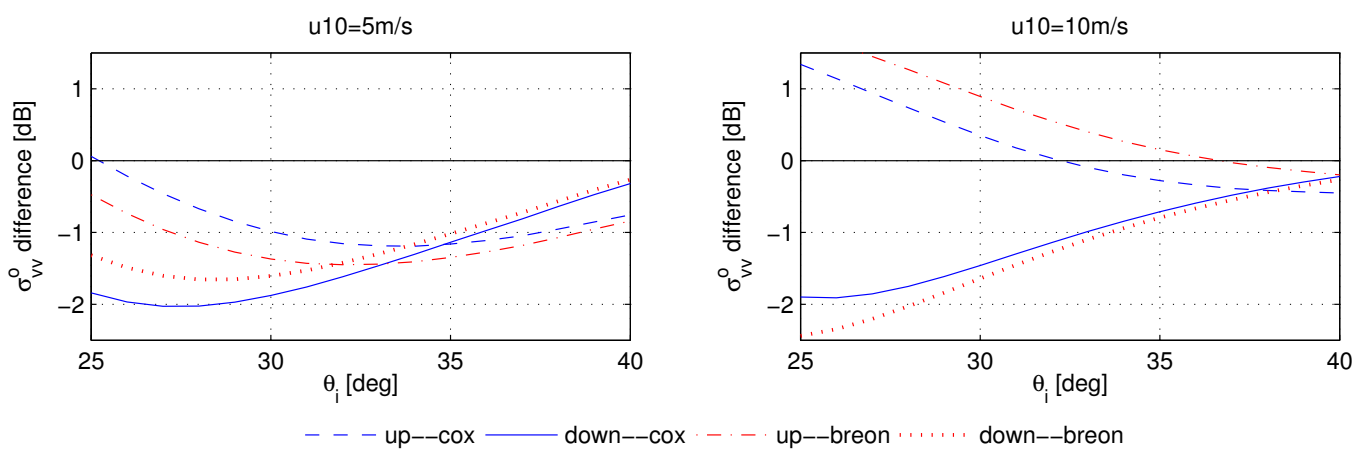

Fig. 13. $\sigma_{V V}^{o}$ difference as a function of incidence angle given an up and downwind directions. This figure respectively compares the performance of simulated $\sigma_{V V}^{o}$ with $\mathrm{CM}$ and $\mathrm{BH}$ based skewness related phase parameters against Cmod5.n. This comparison is done for a 5 and $10 \mathrm{~m} / \mathrm{s} \mathrm{u}_{10}$.
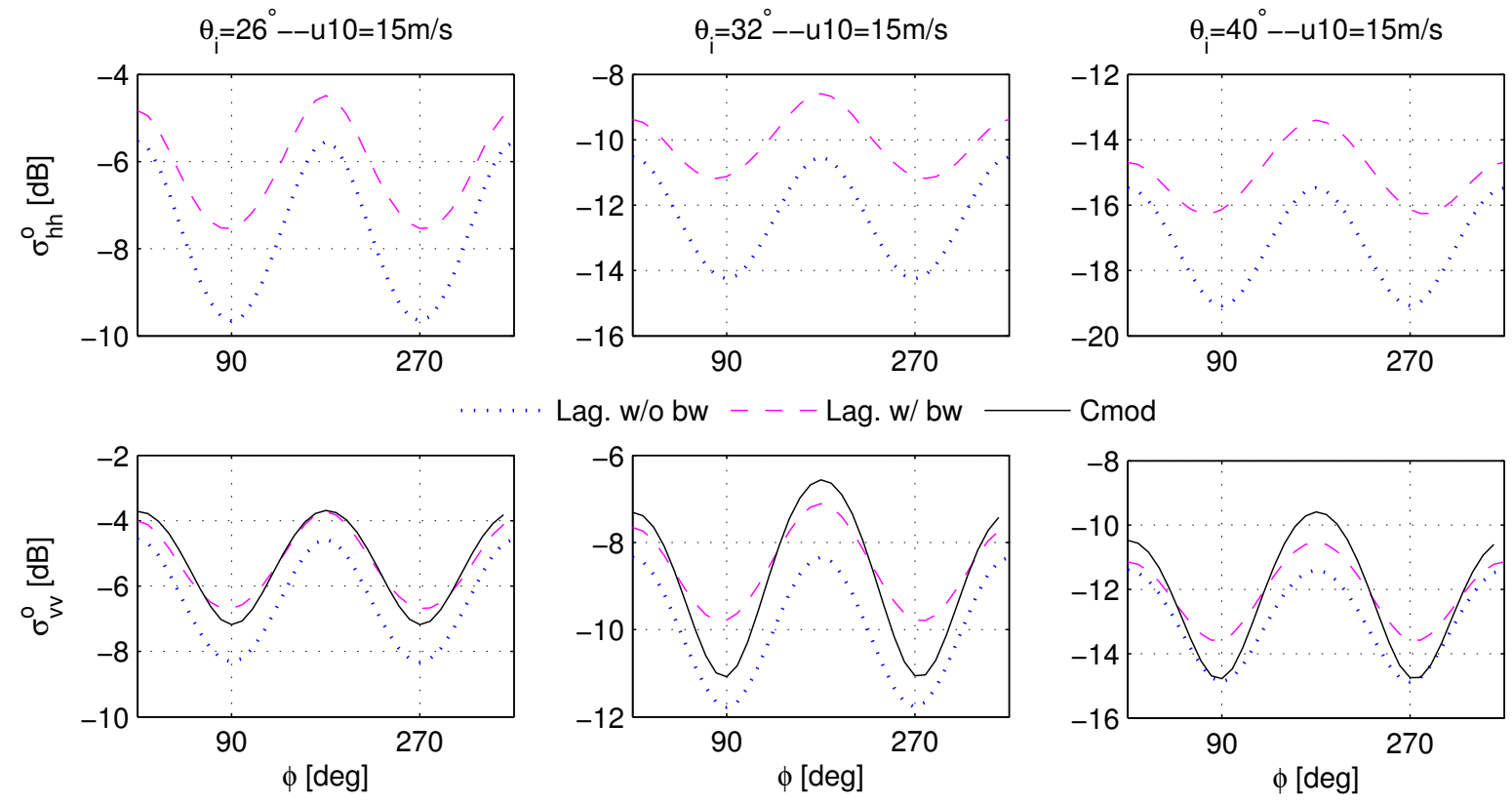

Fig. 14. Comparison of the GCM backscatter model with and without the wave breaking implementation (see [28] and [32] for more details). Selected parameters are $\mathrm{u}_{10}=15 \mathrm{~m} / \mathrm{s}$, and three different incidence angles $(26,32$, and 40 degrees) for both $H H$ and $V V$ polarizations. Cmod5.n is included for reference for the $V V$ polarization.

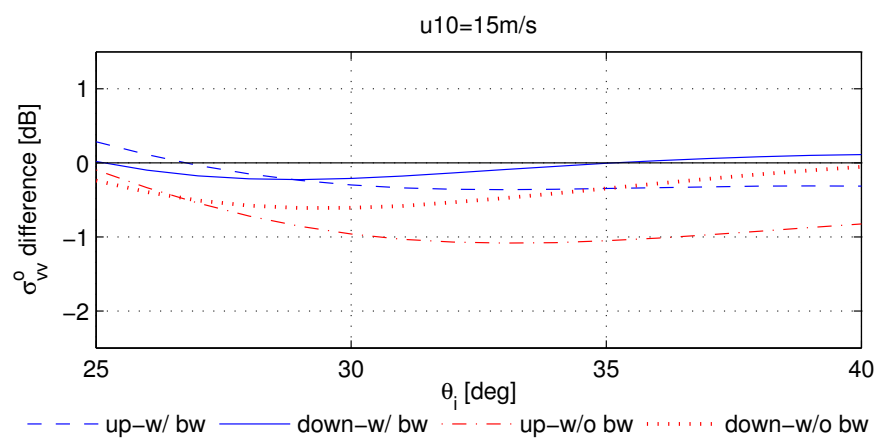

Fig. 15. $\sigma_{V V}^{o}$ difference as a function of incidence angle given an up and downwind directions. This figure respectively compares the performance of simulated $\sigma_{V V}^{o}$ with and without the wave breaking implementation against Cmod5.n. This comparison is done for a $15 \mathrm{~m} / \mathrm{s} \mathrm{u}_{10}$.

In this paper, we have shown that the skewness related phase parameter introduced into the GCM clearly affects the NRCS in the up and downwind directions, for both polarizations, wind speeds less $10 \mathrm{~m} / \mathrm{s}$, and incidence angles between 25 and $40^{\circ}$. The current approach, however, is currently excluding effects from parasitic capillary waves for short gravity waves. The inclusion of the latter should be explored in order to improve the description of the sea surface, as it may dominate the effect of skewness at low wind speeds. We also recognize the fact that the proposed approach essentially introduces a transient effect of the wave motions on the sea surface, which may be still be acceptable in a 'stastistical' sense. Future works could include a repeat of this analysis at various frequency bands (e.g. X- or Ku-band); it would also be interesting to repeat this simulation using the proposed description of the sea surface, but replace the GCM with some other scattering model, in order to see the impact of the skewness related phase parameter on the latter. Finally, the performance of this new approach could be assessed by comparing the NRCS from 
the GCM with those measured from scatterometers or SAR instruments, spatially and temporally collocated with in situ measurements from buoys.

\section{ACKNOWLEDGMENT}

Funding for this work has been provided by the Troms County Regional Development fund (RDA).

\section{REFERENCES}

[1] T. Lungu, QuikSCAT Science Data Product User's Manual: Overview and Geophysical Data Products, version 3.0, Jet Propulsion Lab. Pasadena, Calif., June 2006. [Online]. Available: ftp://podaac.jpl.nasa. gov/pub/ocean_wind/quikscat/doc/QSUG_v3.pdf

[2] L. Ricciardulli and F. Wentz, "Reprocessed QuikSCAT (V04) wind vectors with Ku-2011 geophysical model function," Remote Sensing Systems, Tech. Rep., April 2011. [Online]. Available: http://www.ssmi.com/qscat/qscat_Ku2011_tech_report.pdf

[3] Ocean and S. I. SAF, ASCAT Wind Product User Manual, KNMI, De Bilt, the Nertherlands, August 2011. [Online]. Available: http://www. knmi.nl/scatterometer/publications/pdf/ASCAT_Product_Manual.pdf

[4] K. E. Team, ERS Scatterometer Product User Manual, KNMI, De Bilt, the Nertherlands, November 2008. [Online]. Available: http://www. knmi.nl/scatterometer/publications/pdf/ERS_Product_Manual.pdf

[5] A. Chaudhry and R. Moore, "Tower-based backscatter measurements of the sea," Oceanic Engineering, IEEE Journal of, vol. 9, no. 5, pp. 309-316, 1984.

[6] W. C. Keller, V. Wismann, and W. Alpers, "Tower-based measurements of the ocean c band radar backscattering cross section," Journal of Geophysical Research: Oceans, vol. 94, no. C1, pp. 924-930, 1989. [Online]. Available: http://dx.doi.org/10.1029/JC094iC01p00924

[7] J. Carswell, S. Carson, R. McIntosh, F. K.Li, G. Neumann, D. McLaughlin, J. Wilkerson, P. Black, and S. Nghiem, "Airborne scatterometers: investigating ocean backscatter under low and high-wind conditions," Proceedings of the IEEE, vol. 82, no. 12, pp. 1835-1860, 1994.

[8] H. Masuko, K. Okamoto, M. Shimada, and S. Niwa, "Measurement of microwave backscattering signatures of the ocean surface using $\mathrm{x}$ band and ka band airborne scatterometers," Journal of Geophysical Research: Oceans, vol. 91, no. C11, pp. 13 065-13 083, 1986. [Online]. Available: http://dx.doi.org/10.1029/JC091iC11p13065

[9] J. R. Carswell, W. J. Donnelly, R. E. McIntosh, M. A. Donelan, and D. C. Vandemark, "Analysis of c and ku band ocean backscatter measurements under low-wind conditions," Journal of Geophysical Research: Oceans, vol. 104, no. C9, pp. 20 687-20 701, 1999. [Online]. Available: http://dx.doi.org/10.1029/1999JC900140

[10] F. J. Wentz and D. K. Smith, "A model function for the ocean-normalized radar cross section at $14 \mathrm{ghz}$ derived from nscat observations," Journal of Geophysical Research: Oceans, vol. 104, no. C5, pp. 11499-11 514, 1999. [Online]. Available: http://dx.doi.org/10.1029/98JC02148

[11] A. Bentamy, P. Queffeulou, Y. Quilfen, and K. Katsaros, "Ocean surface wind fields estimated from satellite active and passive microwave instruments," Geoscience and Remote Sensing, IEEE Transactions on, vol. 37, no. 5, pp. 2469-2486, 1999.

[12] A. Long, "C-band v-polarized radar sea-echo model from ers-1 haltenbanken campaign," Journal of Electromagnetic Waves and Applications, vol. 9, no. 3, pp. 373-391, 1995. [Online]. Available: http://www.tandfonline.com/doi/abs/10.1163/156939395X00532

[13] B. S. Gohil, R. Sikhakolli, and R. Gangwar, "Development of geophysical model functions for oceansat-2 scatterometer," Geoscience and Remote Sensing Letters, IEEE, vol. 10, no. 2, pp. 377-380, 2013.

[14] P. K. Taylor, E. C. Kent, M. J. Yelland, and B. I. Moat, "The accuracy of marine surface winds from ships and buoys," in Proc. CLIMAR, WMO Workshop Adv. Marine Climatol., Vancouver, BC, Canada, September 1999 , pp. $59-68$.

[15] V. J. Cardone, E. A. Ceccacci, A. T. Cox, and J. G. Greenwood, "Accuracy of scatterometer winds assessed from in-situ measured wind data up to $32 \mathrm{~m} / \mathrm{s}$," in Spring Meeting of American Geophysical Union, Washington D.C., 2000, no. Paper OS52A-03.

[16] V. R. Swail and A. T. Cox, "On the use of ncepncar reanalysis surface marine wind fields for a long-term north atlantic wave hindcast," J. Atmos. Oceanic Technol., vol. 17, p. 532545, 2000, http://dx.doi.org/10.1175/15200426(2000)017;0532:OTUONN $; 2.0 . C O ; 2$.
[17] S. Soisuvarn, Z. Jelenak, P. Chang, S. Alsweiss, and Q. Zhu, "Cmod5.h x2014; a high wind geophysical model function for c-band vertically polarized satellite scatterometer measurements," Geoscience and Remote Sensing, IEEE Transactions on, vol. 51, no. 6, pp. 3744-3760, 2013.

[18] M. P. Arnús, "Wind Field Retrieval from Satellite Radar Systems," Astronomy and Meteorology Department, University of Barcelona, September 2002.

[19] H. Hersbach, "Comparison of C-Band Scatterometer CMOD5.N Equivalent Neutral Winds with ECMWF," Journal of Atmospheric and Oceanic Technology, vol. 27, pp. 721-736, 2010.

[20] W. J. Plant, "A two-scale model of short wind-generated waves and scatterometry," Journal of Geophysical Research: Oceans, vol. 91, no. C9, pp. 10735-10749, 1986. [Online]. Available: http://dx.doi.org/10.1029/JC091iC09p10735

[21] A. G. Voronovich and V. U. Zavorotny, "Theoretical model for scattering of radar signals in $\mathrm{k} \mathrm{u} \mathrm{-} \mathrm{and} \mathrm{c-bands} \mathrm{from}$ a rough sea surface with breaking waves," Waves in Random Media, vol. 11, no. 3, pp. 247-269, 2001. [Online]. Available: http://www.tandfonline.com/doi/abs/10.1080/13616670109409784

[22] M. A. Donelan and W. J. Pierson, "Radar scattering and equilibrium ranges in wind-generated waves with application to scatterometry," Journal of Geophysical Research: Oceans, vol. 92, no. C5, pp. 4971-5029, 1987. [Online]. Available: http://dx.doi.org/10.1029/JC092iC05p04971

[23] K. Chen, A. Fung, and D. Weissman, "A backscattering model for ocean surface," Geoscience and Remote Sensing, IEEE Transactions on, vol. 30, no. 4, pp. 811-817, 1992.

[24] J. A. Johannessen, B. Chapron, F. Collard, V. Kudryavtsev, A. Mouche, D. Akimov, and K.-F. Dagestad, "Direct ocean surface velocity measurements from space: Improved quantitative interpretation of Envisat ASAR observations," Geophys. Res. Lett., vol. 35, November 2008.

[25] F. T. Ulaby, R. K. Moore, and A. K. Fung, Microwave Remote Sensing: Active and Passive Volume II: Radar Remote Sensing and Surface Scattering and Emission Theory, D. S. Simonett, Ed. Addison-Wesley, 1982.

[26] P. Beckmann and A. Spizzichino, The Scattering of Electromagnetic Waves from Rough Surfaces. MacMillan, 1963, vol. 4.

[27] G. Engen, I. Friestad-Pedersen, H. Johnsen, and T. Elfouhaily, "Curvature effects in ocean surface scattering," IEEE Transactions on Antennas and Propagation, vol. 54, no. 5, pp. 1370-1379, May 2006.

[28] H. Johnsen, G. Engen, and G. Guitton, "Sea-surface polarization ratio from envisat ASAR AP data," IEEE Transactions on Geoscience and Remote Sensing, vol. 46, no. 11, pp. 3637-3646, November 2008.

[29] F. Said and H. Johnsen, "Sea surface wind retrieval using both normalized radar cross section and polarization residual doppler frequency from TerraSAR-X data," in Geoscience and Remote Sensing Symposium (IGARSS), 2012 IEEE International, July 2012, pp. 2063 -2066.

[30] _ , "Ocean surface wind retrieval from dual-polarized sar data using the polarization residual doppler frequency," Geoscience and Remote Sensing, IEEE Transactions on, vol. 52, no. 7, pp. 3980-3990, Sep 2013.

[31] W. J. Plant, "A stochastic, multiscale model of microwave backscatter from the ocean," Journal of Geophysical Research: Oceans, vol. 107, no. C9, pp. 3-1-3-21, 2002, 3120. [Online]. Available: http://dx.doi.org/10.1029/2001JC000909

[32] V. Kudryavtsev, D. Hauser, G. Caudal, and B. Chapron, "A semiempirical model of the normalized radar cross-section of the sea surface," Journal of Geophysical Research, vol. 108, no. C3, p. 8054, 2003.

[33] A. A. Mouche, B. Chapron, N. Reul, D. Hauser, and Y. Quilfen, "Importance of the sea surface curvature to interpret the normalized radar cross section," Journal of Geophysical Research: Oceans, vol. 112, no. C10, pp. n/a-n/a, 2007, c10002. [Online]. Available: http://dx.doi.org/10.1029/2006JC004010

[34] A. S. Mironov, M. V. Yurovskaya, V. A. Dulov, D. Hauser, and C. A. Gurin, "Statistical characterization of short wind waves from stereo images of the sea surface," Journal of Geophysical Research: Oceans, vol. 117, no. C12, pp. n/a-n/a, 2012, c00J35. [Online]. Available: http://dx.doi.org/10.1029/2011JC007860

[35] C. Cox and W. Munk, "Measurement of the roughness of the sea surface from photographs of the sun's glitter," J. Opt. Soc. Am., vol. 44, no. 11, pp. 838-850, Nov 1954. [Online]. Available: http://www.opticsinfobase.org/abstract.cfm?URI=josa-44-11-838

[36] O. M. Phillips, The dynamics of the upper ocean. Cambridge University Press, 1977, ISBN 0-521-21421-1.

[37] M. S. Longuet-Higgins, "Eulerian and lagrangian aspects of surface waves," Journal of Fluid Mechanics, vol. 173, pp. 683-707, December 1986. 
[38] F. Nouguier, C.-A. Guérin, and B. Chapron, "choppy wave model for nonlinear gravity waves," Journal of Geophysical Research, vol. 114, no. C0, p. 9012, 2009.

[39] G. Engen, P. W. Vachon, H. Johnsen, and F. W. Dobson, "Retrieval of ocean wave spectra and rar mtf's from dual-polarization SAR data," IEEE Transactions on Geoscience and Remote Sensing, vol. 38, no. 1, pp. 391-403, January 2000

[40] B. Chapron, D. Vandemark, and T. Elfouhaily, On the Skewness of the Sea Slope Probability Distribution. American Geophysical Union, 2013, pp. 59-63. [Online]. Available: http://dx.doi.org/10.1029/ GM127p0059

[41] F. M. Bréon and N. Henriot, "Spaceborne observations of ocean glint reflectance and modeling of wave slope distributions," Journal of Geophysical Research: Oceans, vol. 111, no. C6, pp. n/a-n/a, 2006. [Online]. Available: http://dx.doi.org/10.1029/2005JC003343

[42] T. Elfouhaily, B. Chapron, K. Katsaros, and D. Vandemark, "A unified directional spectrum for long and short wind-driven waves," Journal of Geophysical Research - Oceans, vol. 102, no. C7, pp. 15,781-15,796, 1997.

[43] V. N. Kudryavtsev, V. K. Makin, and B. Chapron, "Coupled sea surface-atmosphere model: 2. spectrum of short wind waves," Journal of Geophysical Research: Oceans, vol. 104, no. C4, pp. 7625-7639, 1999. [Online]. Available: http://dx.doi.org/10.1029/1999JC900005

[44] I. F. Pedersen, G. Engen, and H. Johnsen, "Polarization dependency in sea surface Doppler frequency and its application to envisat ASAR alt-pol data," in Envisat and ERS Symposium. Norut Information Technology, September 2004

[45] F. Said and H. Johnsen, "Assessment of ocean wind retrieval from dualpolarized x-band SAR data," Synthetic Aperture Radar, 2012. EUSAR, 9th European Conference on, pp. 653 -656, April 2012.

[46] F. Nouguier, C.-A. Guérin, and B. Chapron, "Scattering from nonlinear gravity waves: The choppy wave model," Geoscience and Remote Sensing, IEEE Transactions on, vol. 48, no. 12, pp. $4184-4192$, December 2010

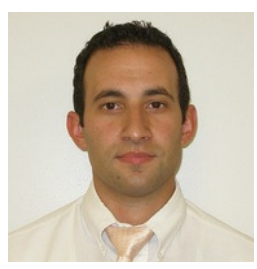

Faozi Saïd (S'07-M'15) received the M.Sc. degree in electrical engineering from Brigham Young University (BYU), Provo, UT, in 2009 and the Ph.D. degree in Physics from the University of Troms $\varnothing$, Troms, Norway in 2015. From 2012 to 2014, he was also a Guest Research Scientist at the Spatial Oceanography Laboratory (LOS), French Research Institute for Exploitation of the Sea (IFREMER) in Brest, France. He is currently working for Global Science Technology, Inc. as a research scientist with the Ocean Surface Winds Team at the Center for Satellite Application and Research (STAR), National Environmental Satellite Data and Information Service (NESDIS), National Oceanic and Atmospheric Administration (NOAA). His current research interests include sea surface wind retrieval algorithm development for both active and passive microwave remote sensing instruments including the Scatsat-1 and NASA Cyclone Global Navigation Satellite System (CYGNSS) missions. His work also includes data calibration and validation of these two missions.

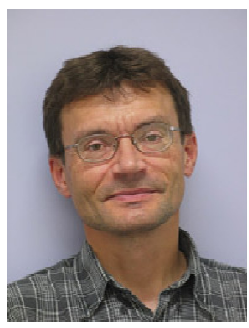

Harald Johnsen received the M.Sc. degree in 1981 and the Ph.D. in 1984 from the University of Troms $\varnothing$, Troms $\varnothing$, Norway. After graduating, he worked two years at the Auroral Observatory in Troms $\varnothing$ before joining Norut IT, Troms $\varnothing$, in 1986 as a Research Scientist within the Earth Observation Group. From 1994 to 2002, he was the Research Manager at the same institution with responsibility for the remote sensing activities. His main research interest at present is within SAR ocean applications and SAR interferometry applications.

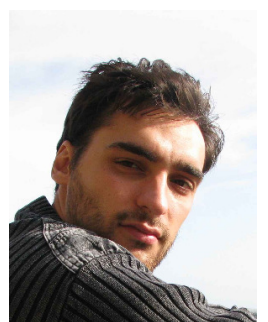

Frédéric Nouguier received the "Agrégation" and the M.S. degrees in applied physics from the Ecole Normale Supérieure de Cachan, France, in 2005 and 2006, respectively, the M.S. degree in physical methods for remote sensing from the University of Paris-Diderot, Paris, France, in 2006, and the Ph.D. degree in physics from the University of Marseille, France, in 2009. From 2009 to 2010, he was a Postdoctoral Fellow with the French Research Institute for Exploitation of the Sea (IFREMER), Brest, France. He is now a Research Scientist at the Laboratoire d'Océanographie Physique et Spatiale (LOPS), IFREMER, Plouzané, France. He has experience in applied mathematics, physical oceanography, and electromagnetic wave theory and its application to ocean remote sensing.

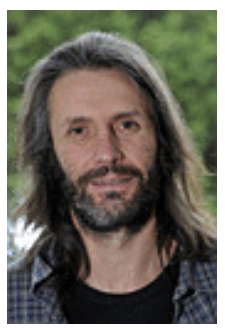

Bertrand Chapron received his Ph.D. degree in physics (fluid mechanics) from the University of Aix-Marseille II, Marseille, France, in 1988. He spent three years as a Postdoctoral Research Associate with the NASA Goddard Space Flight Center, Greenbelt, MD, at the Wallops Flight Facility, Wallops Island, VA. He is presently a Senior Research Scientist with the Laboratoire d'Océanographie Physique et Spatiale, Institut Français de Recherche et d'Exploitation de la Mer, Plouzané, France. He is a co-investigator and Principal Investigator in several European Space Agency, NASA, and CNES projects. He has experience in applied mathematics, physical oceanography, and electromagnetic wave theory and its application to ocean remote sensing.

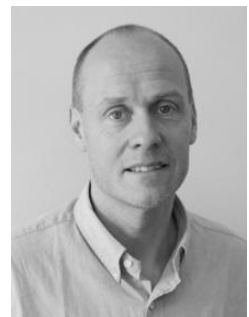

Geir Engen received the M.Sc. degree from the University of Troms in 1991 and his Ph.D. degree from Norut and the University of Troms in 1997. He has since then been working as a research scientist at Norut, except for a six months period at Forsvarets Forskningsinstitutt, Kjeller. He visited NASA Goddard Space Flight Center, Maryland, from October 1993 to September 1994. He has also visited IFREMER as a guest research scientist. His experience and interest lie within processing and oceanographic Synthetic Aperture Radar. applications of microwave radar, with main focus on 